\title{
Ballistic investigation of polymer bonded borided steel sheets
}

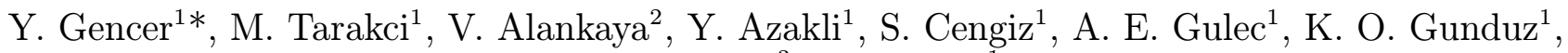 \\ A. S. Oktem ${ }^{3}$, Z. C. Oter \\ ${ }^{1}$ Gebze Technical University, Department of Materials Science and Engineering, Gebze, Turkey \\ ${ }^{2}$ Turkish Naval Academy, Department of Naval Architecture, Istanbul, Turkey \\ ${ }^{3}$ Gebze Technical University, Department of Mechanical Engineering, Gebze, Turkey
}

Received 17 March 2017, received in revised form 8 February 2017, accepted 9 February 2017

\begin{abstract}
In this study, it was aimed to produce composite laminates of boronized AISI-1010 steel plates as an alternative protection against the threat level BR-2 defined in the EN-1063 standard. Cold rolled AISI-1010 steel plates were cut into hexagonal plates with $45 \mathrm{~mm}$ diagonals. These hexagonal plates were boronized by pack boronizing method at $950^{\circ} \mathrm{C}$ for $3 \mathrm{~h}$. The characterization of the boronized samples was carried out by SEM-EDS, XRD, and Vickers microhardness measurement. Composite laminates having two different thicknesses were produced by bonding boronized AISI-1010 steel plates with a binary component acrylic adhesive and pressing. Armor plates were produced by combining hexagonal composite laminates together on a thin kevlar sheet to provide the necessary integrity. The ballistic tests of these plates were performed for the threat level BR-2 defined in the EN-1063 standard.
\end{abstract}

K e y words: armor, laminated composite panel, ballistic damage, boronizing, iron boride

\section{Introduction}

Development of lightweight materials for ballistic protection has been a consistent effort for decades $[1-$ 16]. The analytical complexity of impact phenomena forms this research to be covered by approximate numerical methods and extensive experiments. To reduce armor weight, the analyst takes into consideration the complicated loading mechanism and the deformation interaction of different materials such as brittle ceramics and elastic composites of high strength and high modulus.

Wambua [17] defines that use of ceramics for body armor due to the weight considerations has continued to decrease over the years. Although they have the capability to decrease strike velocity, their brittleness resulted in the usage of backing materials [18-20]. Therefore, two factors lead the research to be grown in the composition of these materials: (i) the necessity of ceramic toughness and backing elasticity, (ii) the correlation between ceramic brittle deformation and energy absorption capability of backing lamination.

According to authors' knowledge, one of the early studies about the impact resistance of the laminated ceramic tiles compared to that of monolithic ceramic at the same thickness is the experiment presented by Yadav and Ravichandran [21]. They concluded that penetration resistance of an unconfined ceramic structure could be improved significantly by laminating ceramic tiles with thin polymer layers between them.

Similar studies are presented comparing the efficiency of elastic layer usage between the ceramic front layer and composite backing [22-25]. Rubber, teflon, woven kenaf, metal foam, and polymers are used as the insertion of an interlayer between ceramic and composite layers. The common conclusion is that these additional layers significantly reduce the wave propagation velocity and play a key role in the ballistic performance of the armor system. Also, this enhanced performance is attributed to the crack arresting feature of the polymer layer [21].

In this study, a novel material model is produced to compound the advantage of ceramic toughness by surface hardening and elasticity of steel. Moreover, polymers are used between the plies in the lamination of thin plies providing not only to perform the full body

*Corresponding author: tel.: +90 26260526 64; e-mail address: gencer@gtu.edu.tr 
integration but also reduce the wave propagation. Experiments are performed for the threat level BR-2 defined in EN-1063 standard [26]. The main motivation of the study is to clarify the ballistic impact resistance of this novel material by taking into account its deformation behavior. In the literature, the effect of such lamination on the ballistic performance of boronized steel laminated composites is missing.

\section{Production of hexagonal shaped boronized plies}

$300 \mu \mathrm{m}$ thick AISI-1010 cold rolled steel plates were laser cut into hexagonal plates with $45 \mathrm{~mm}$ diagonals. Surfaces of these hexagonal plates were cleaned and degreased using suitable chemicals, water, and alcohol. Hexagonal plates were then embedded into commercial Ekabor II powder in a stainless steel crucible, covered with alumina powder and sealed using a stainless steel lid to prevent oxidation during boronizing. The boronizing process was carried out at $950{ }^{\circ} \mathrm{C}$ for $3 \mathrm{~h}$ in an electrical resistance box furnace under atmospheric conditions, and the boronized plates inside the sealed crucible were cooled to room temperature outside the furnace. Figure 1 shows a schematic of the boronizing system.

After the boronizing process, the surfaces of the boronized plates were cleaned by an ultrasonic cleaner in alcohol. Samples were cut into two pieces for further analysis. A Rigaku D-MAX 2200X-Ray diffractometer was employed with a $\mathrm{Cu} \mathrm{K} \alpha$ radiation over a $2 \theta$ range from $20^{\circ}$ to $90^{\circ}$ to determine the phases formed on the surface of the boronized samples. One piece of each

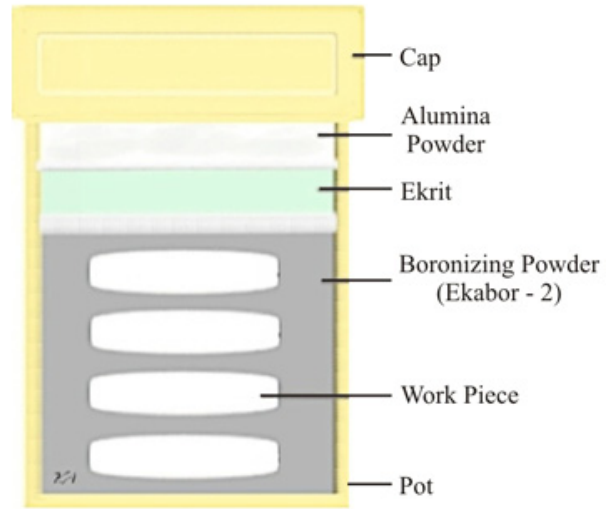

Fig. 1. A schematic figure of the boronizing system.

sample was embedded in epoxy resin, ground with 801200 grid emery paper and polished using alumina to expose the cross section of the boride layer.

\section{Control measurements of the plies}

Cross-sectional microstructure examination and elemental analysis were carried out using Philips XL 30 Scanning Electron Microscope (SEM) with an Energy Dispersive Spectrometer (EDS) detector as well as a Nikon Eclipse LV150 Optical Microscope.

Vickers hardness of boronized layers was measured over the indents on the cross section obtained by an application of $30 \mathrm{~g}$ load using a Mitutoyo microhardness tester.

Figure 2 shows XRD patterns obtained from the

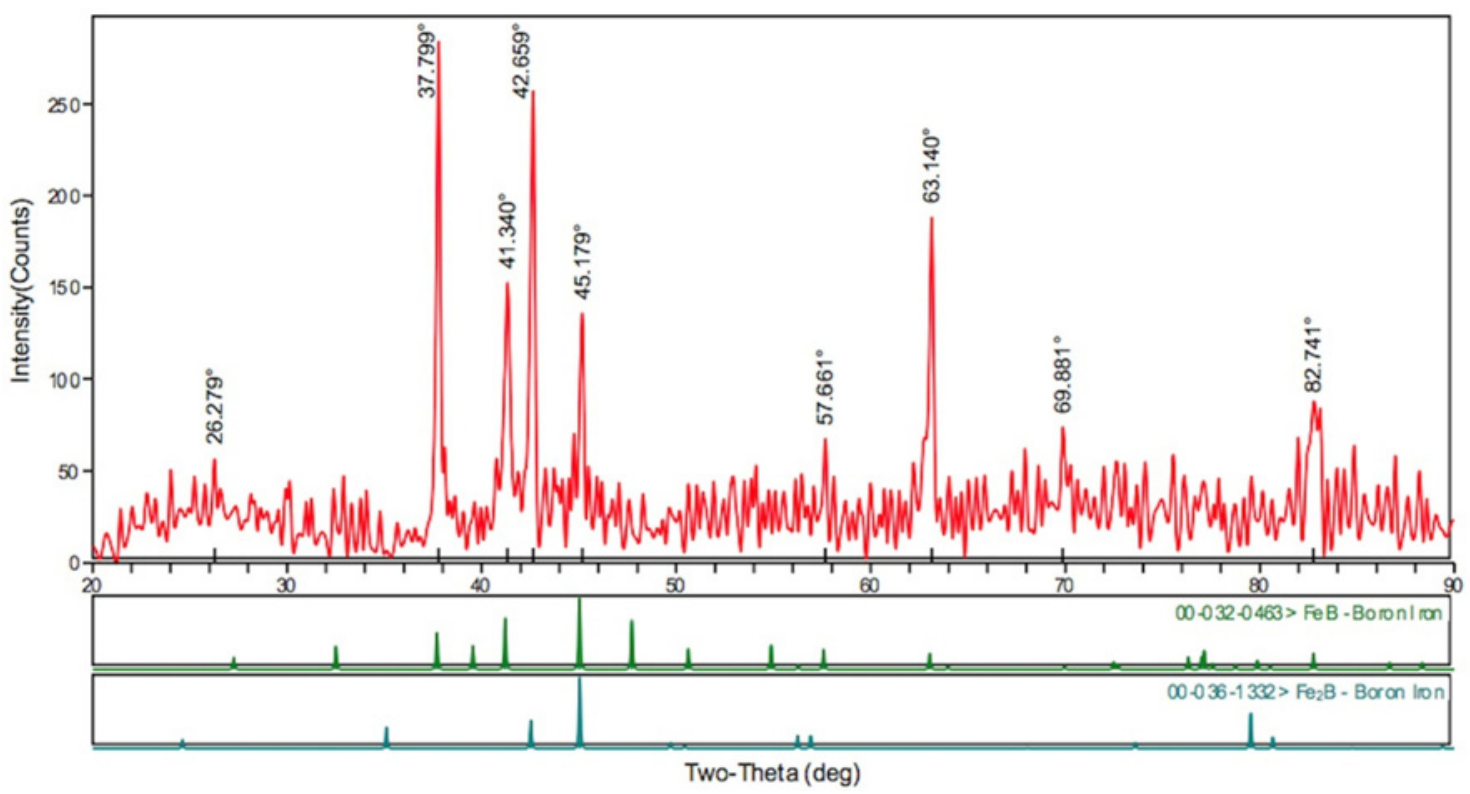

Fig. 2. XRD spectrum obtained from the surface of the steel plate boronized at $950^{\circ} \mathrm{C}$ for $3 \mathrm{~h}$. 


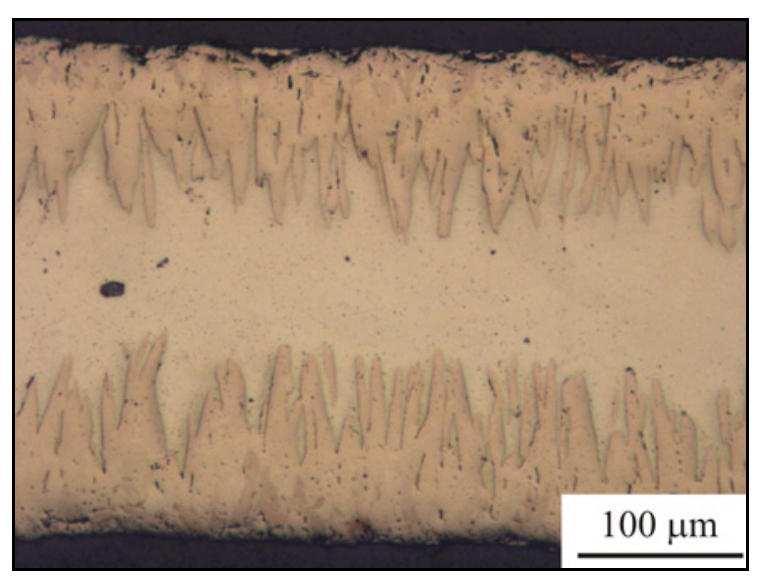

Fig. 3. The cross-sectional optical microscope image of the steel plate boronized at $950^{\circ} \mathrm{C}$ for $3 \mathrm{~h}$.

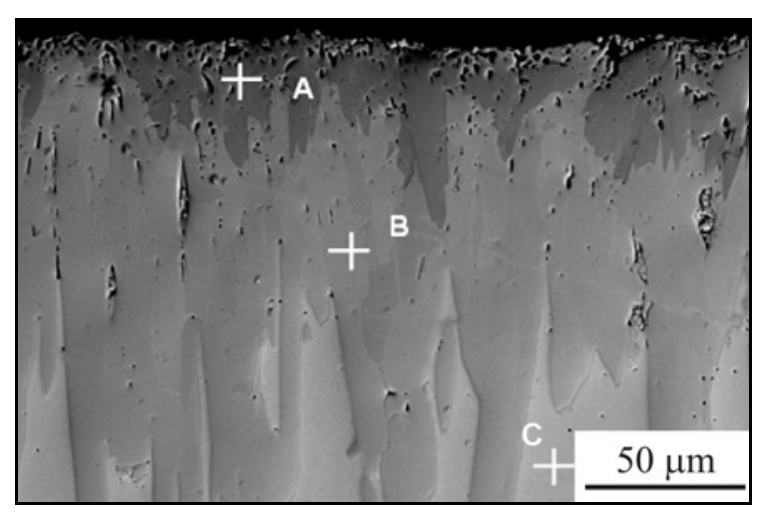

Fig. 4. The cross-sectional SEM micrograph.

surface of the steel plate boronized at $950{ }^{\circ} \mathrm{C}$ for $3 \mathrm{~h}$. The XRD patterns show that the boride layer is composed of $\mathrm{FeB}$ and $\mathrm{Fe}_{2} \mathrm{~B}$ phases.

Figure 3 illustrates the cross-sectional optical microscope micrograph of the steel plate boronized at $950^{\circ} \mathrm{C}$ for $3 \mathrm{~h}$. The figure shows that the boride layer is composed of two regions: (i) light colored region located inside the coating, and (ii) the dark colored region located outside the coating. It is usually reported in the literature that the outer region is $\mathrm{FeB}$ and the inner region is $\mathrm{Fe}_{2} \mathrm{~B}$ for the boronized ferrous materials. XRD results also show that the formation of $\mathrm{FeB}$ and $\mathrm{Fe}_{2} \mathrm{~B}$ is evident. $\mathrm{Fe}_{2} \mathrm{~B}$ phase forms firstly during the boronizing, and it inhibits the diffusion of boron. As a result of this, FeB phase (boron-rich) forms in the outer region of the boride layer. It can be clearly seen from the Fig. 3 that the boride layer well adheres to the substrate and the adhesion is supported with the saw tooth like morphology as the interface area is significantly high. The coating thickness is measured between 50 and $120 \mu \mathrm{m}$.

Figures 4 and 5 show the cross-sectional SEM micrograph and SEM-EDS spectrum of the steel plate boronized at $950^{\circ} \mathrm{C}$ for $3 \mathrm{~h}$. The spectra were obtained from certain points signed as a $(+)$ and named as "A," "B", and "C" in a SEM micrograph in Fig. 4. The SEM-EDS spectra obtained from points A, B, and C show that boride layers are composed of iron (Fe) and boron (B). The SEM-EDS spectrum obtained from point $\mathrm{C}$ reveals that iron $(\mathrm{Fe})$ content is higher than that from points $\mathrm{A}$ and $\mathrm{B}$. Content of boron (B) is almost the same in three regions.

Figure 6 represents average microhardness values obtained from the boride layer and substrate through the cross section of the sample. The average hardness value of the boride layer is approximately $2000 \mathrm{HV}$. Microhardness of the crude steel is approximately $275 \mathrm{HV}$. After boriding process microhardness of the substrate sharply decreases about $90 \mathrm{HV}$ owing to softening by heat.

\section{Experimental setup}

13 layered composite laminates were produced by the following procedure. A binary component acrylic adhesive was applied to the surfaces of each hexag-
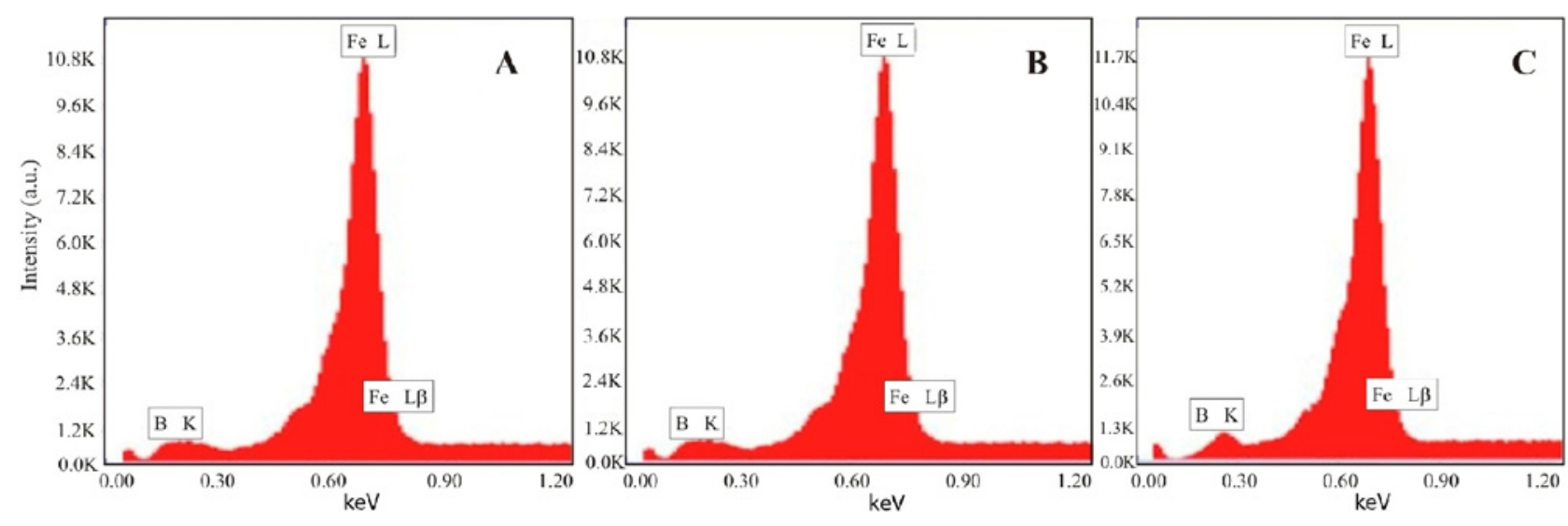

Fig. 5. SEM-EDS spectra of the steel plate boronized at $950{ }^{\circ} \mathrm{C}$ for $3 \mathrm{~h}$. 


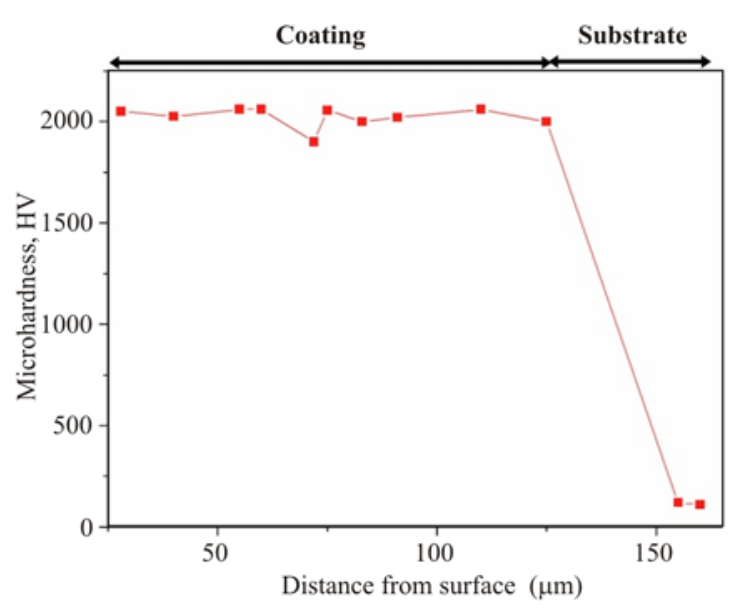

Fig. 6. Variation of the average microhardness values with distance through the cross-section of the boride layer.
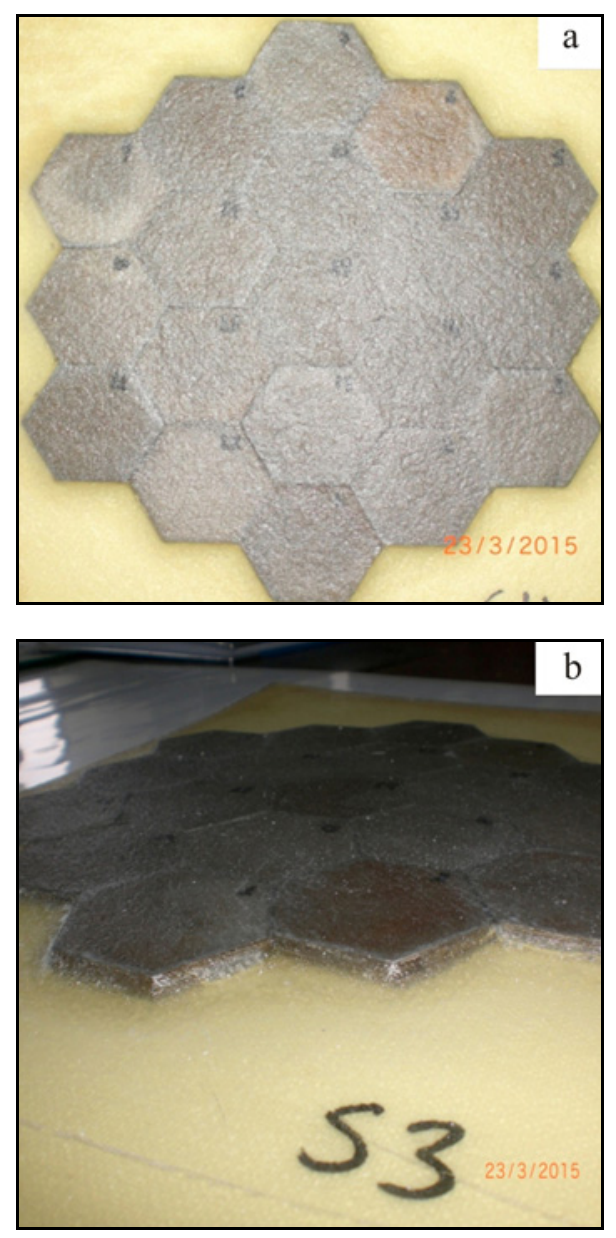

Fig. 7. Macroscopic image of composite laminates combined to form an armor plate with hexagonal symmetry.

onal plate. These plates were then aligned on top of each other and pressed for $2 \mathrm{~h}$ until the polymer adhesive was completely cured. A thin kevlar sheet was

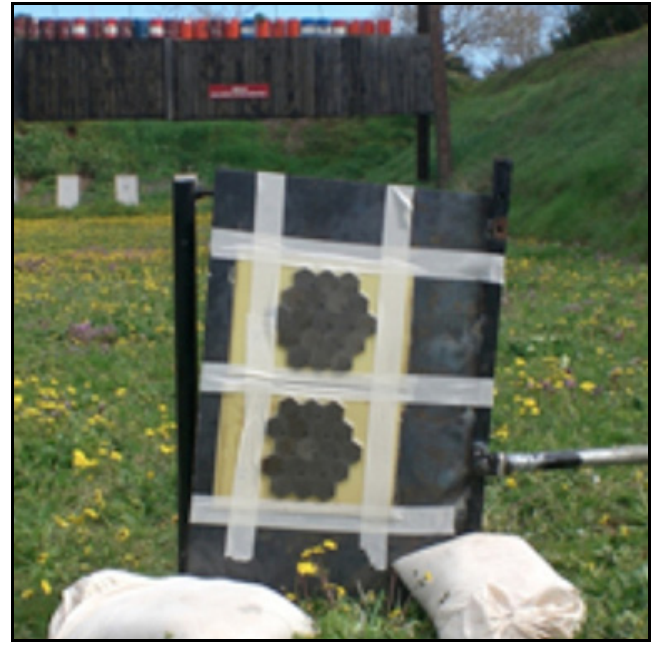

Fig. 8. Ballistic tests are performed at an outdoor shooting gallery.

used to combine 19 composite laminates to produce armor plates for ballistic testing (Fig. 7). Laminates were aligned on the kevlar sheet in a way to preserve the hexagonal symmetry, fixed by hand lay-up method using epoxy resin and autoclaved.

Ballistic tests were performed at an outdoor shooting gallery (Fig. 8) according to distance limits defined in EN-1063 standard [26] for the threat level BR-2. Light weight small caliber submachine gun (MP5) was used with the muzzle velocity of $400 \mathrm{~m} \mathrm{~s}^{-1}$ with $9 \times 19 \mathrm{~mm}^{2}$ bullets. Test samples were supported by their boundaries of hexagonally formed armor surface. Targets were hit at the centers of individual hexagons with a suitable distance from the neighbor border. Composite laminates were shot, and the macro and micro observations were carried out to determine the structural impact damage.

\section{Results}

The expected failure mechanism for the ceramic faced armor plates consisting of laminates bonded together through epoxy layers is that the first plies are broken upon impact, but the next layers may be intact. As well as tensile radial crack deformation, cone formation or pulverizing conoid structure of ceramic faced layers, petalling is expected at backing layers depending on the penetration. Moreover, the energy absorbing mechanism of the armor system results in delamination or separation through the layers or between the ceramic and backing layers.

The post-impact inspection of the armor plates introduced that the samples were unable to stop the projectile. There was no delamination or separation observed through the ceramic layers. Further, there 


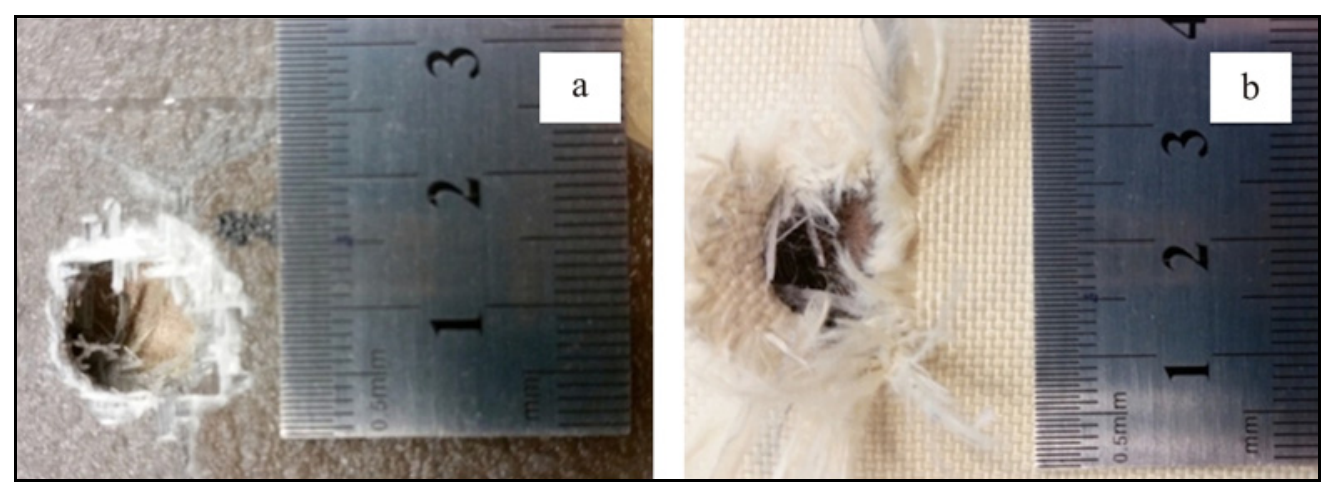

Fig. 9. The post-impact inspection of the armor plates: (a) strike face, (b) backface.

was no pulverization on the strike face layers as can be seen in Fig. 9a. Despite hardening by boronization, steel plies demonstrated intensive shattering and crack propagation resulting in the complete disintegration of the impact zone.

Inspection of backing layers introduced the petalling and fiber cracking deformations of kevlar backing plies. There was no dish or bulge deformation observed on the backface as can be seen in Fig. 9b. This behavior can be concluded as the result of the absence of stress or deformation gradients. Moreover, this type of failure can be classified as plugging which is the result of a nearly cylindrical slug of the same diameter as the bullet set in motion by the projectile.

The large deformation of the test samples is thought to be due to the relatively lower toughness and ductility of the laminated boronized layers. The reflected or generated tensile waves after projectile impact were not covered by the hexagonal shaped layered plates successfully. Although the hardness of the laminated plates was relatively significant, the armor system was unable to stop projectile penetration. The armor system is weak due to the insufficient erosion of the projectile penetrating through the laminated boronized steel layers. However, if the front layers of the ballistic plate were thick enough, the system could successfully stop the projectile penetration.

\section{Conclusions}

The sample armor system did not show a strong ballistic protection at the investigated thickness and composition. To get a reliable protection, the thickness of the laminated boronized layers would be higher. Nevertheless, in such a case the armor system would not be a good solution to make a lightweight armor production. Boronized steel plies demonstrated intensive shattering and crack propagation results in complete disintegration of the impact zone. The backing layers introduced the petalling and fiber cracking deformation with no dish or bulge deformation. This behavior can be concluded as the result of the absence of stress or deformation gradients which can be observed in relatively thin targets. It is planned to develop this work with thicker laminations and more efficient lamination techniques of boronized steel plies in the future studies.

\section{Acknowledgement}

This work was supported by the Research Fund of TÜBİTAK, Project \# 213M166. The authors are thankful to TÜBİTAK for its support.

\section{References}

[1] Naik, N. K., Shirao, P., Reddy, B. C. K.: Materials Science and Engineering A, 412, 2005, p. 104. doi:10.1016/j.ijimpeng.2005.01.004

[2] Mamivand, M., Liaghat, G. H.: Int. J. of Impact Engineering, 37, 2010, p. 806. doi:10.1016/j.ijimpeng.2010.01.003

[3] Hetherington, J. G.: Int. J. of Impact Engineering, 18, 1995 , p. 319. doi:10.1016/0734-743X(96)89052-X

[4] Corbett, G. G., Reid, S. R., Johnson, W.: Int. J. of Impact Engineering, 18, 1996, p. 141. doi:10.1016/0734-743X(95)00023-4

[5] Goldsmith, W.: Int. J. of Impact Engineering, 22, 1999, p. 95. doi:10.1016/S0734-743X(98)00031-1

[6] Ben-Dor, G., Dubinsky, A., Elperin, T.: Applied High-Speed Plate Penetration Dynamics. Dordrecht, Springer Netherlands 2006. doi:10.1007/1-4020-4239-6

[7] Ben-Dor, G., Dubinsky, A., Elperin, T.: Applied Mechanics Reviews, 58, 2005, p. 355. doi:10.1115/1.2048626

[8] Abrate, S.: Impact on Composite Structures. Cambridge, Cambridge University Press, 1998. ISBN: 9780-521-47389-7

[9] Reid, S. R., Zhou, G. (Eds.): Impact Behaviour of Fibre-Reinforced Composite Materials and Structures. Cambridge, Woodhead Publishing Ltd 2000. ISBN: 185573-423-0

[10] Wen, H. M.: Composite Structures, 49, 2000, p. 321. doi:10.1016/S0263-8223(00)00064-7

[11] Wen, H. M.: Composite Science and Technology, 61, 2001, p. 1163. doi:10.1016/S0266-3538(01)00020-3 
[12] Ansar, M., Xinwei, W., Chouwei, Z.: Composite Structures, 93, 2011, p. 1947. doi:10.1016/j.compstruct.2011.03.010

[13] Jordan, J. B., Naito, C. J.: Int. J. of Impact Engineering, 37, 2010, p. 530. doi:10.1016/j.ijimpeng.2009.11.002

[14] Jordan, J. B., Naito, C. J.: Int. J. of Impact Engineering, 63, 2014, p. 63. doi:10.1016/i.ijimpeng.2013.08.002

[15] Johnson, H. E., Louca, L. A., Mouring, S., Fallah, A. S.: Int. J. of Impact Engineering, 36, 2009, p. 25. doi:10.1016/j.ijimpeng.2008.01.013

[16] Tita, V., Carvalho, J., Vandepitte, D: Composite Structures, 83, 2008, p. 413. doi:10.1016/j.compstruct.2007.06.003

[17] Wambua, P., Vangrimde, B., Lomov, S., Verpoest, I.: Composite Structures, 77, 2007, p. 232. doi:10.1016/i.compstruct.2005.07.006

[18] Ramadhan, A. A., Abu Talib, A. R., Mohd Rafie, A. S., Zahari, R.: Materials and Design, 43, 2013, p. 307. doi:10.1016/i.matdes.2012.06.034
[19] Ubeyli, M., Yildirim, R. O., Ogel, B.: Material Design, 28, 2007, p. 1257. doi:10.1016/i.matdes.2005.12.005

[20] Ubeyli, M., Yildirim, R. O., Ogel, B.: J. of Materials Processing Technology, 196, 2008, p. 356. doi:10.1016/j.jmatprotec.2007.05.050

[21] Yadav, S., Ravichandran, G.: Int. J. of Impact Engineering, 28, 2003, p. 557. doi:10.1016/S0734-743X(02)00122-7

[22] Tasdemirci, A., Tunusoglu, G., Güden, M.: Int. J. of Impact Engineering, 44, 2012, p. 1. doi:10.1016/i.ijimpeng.2011.12.005

[23] Tasdmirci, A., Hall, I. W.: Materials and Design, 30, 2009, p. 1533. doi:10.1016/j.matdes.2008.07.054

[24] Garcia-Avila, M., Portanova, M., Rabiei, A.: Procedia Materials Science, 4, 2014, p. 151. doi:10.1016/i.mspro.2014.07.571

[25] Yahaya, R., Sapuan, S. M., Jawaid, M., Leman, Z., Zainudin, E. S.: Measurement, 77, 2015, p. 335. doi:10.1016/j.measurement.2015.09.016

[26] European Standard EN-1063. Security Glazing - Testing and Classification of Resistance Against Bullet Attack, 1999. 